\title{
Reform and Exploration for Practical Teaching of Electrical Engineering and Automation
}

\author{
Desheng Liu ${ }^{1}$, Zhiru Xu${ }^{1}$, Chunjiang $\mathrm{Li}^{2 \mathrm{a}, \star}$, Xiaojun $\mathrm{Ma}^{3}$, Lei wang ${ }^{1}$ \\ ${ }^{1}$ School of Information and electronic technology, Jiamusi University, Jiamusi, 154007, China; \\ 2Dean's office, Jiamusi University, Jiamusi, 154007, China; \\ ${ }^{3}$ School of Mechanical Engineering Jiamusi University, Jiamusi, 154007, China. \\ ajmslcj@sohu.com
}

Keywords: Practice Teaching Mode, Project Driven, Virtual Simulation.

\begin{abstract}
With the reform of higher education Chinese enrollment mode, professional enrollment differentiation is more and more serious, students majoring in electrical engineering and automation have been developed scale unceasingly, in order to improve the electrical engineering and automation professional theory and practice teaching, improve students' comprehensive quality and effective electrical engineering and automation and describes the practice teaching reform measures, in this paper, the reform measures of practice teaching are expounded, through professional practice teaching, $\mathrm{t}$ teaching effect and cultivate students' engineering application ability are improved and the innovation ability played a certain role
\end{abstract}

\section{Introduction}

Engineering and technical personnel has been training specialty of electric engineering and automation, they should have electrical technology, electronic technology, control theory, computer application technology, power system and automation professional knowledge, to maintenance and operation in power system dispatching of rural power system operation, automatic control and protection, development and utilization of the smart grid and new energy research and development Electrical and electronic products [3]. According to the professional courses are highly practical, practical teaching is an important link to improve students' innovation ability, the professional engineering quality, is the effective way to optimize the students' professional knowledge structure and quality [1].

\section{Present Situation of Professional Practice Teaching}

\subsection{Section Headings.}

With the deepening of the teaching reform in Colleges and universities, the teaching hours of specialized courses have been reduced, and the traditional teaching mode has been kept in the undergraduate teaching. The students are in a passive position in theory teaching and cannot fully mobilize the enthusiasm of the students. The disconnection between theory teaching and practice teaching is quite common, and the arrangement is not reasonable. The traditional teaching model first teaches theoretical knowledge, and then experimental verification. Due to the lack of knowledge of knowledge, students' learning effect is not good, cannot reach the goal of professional skills and professional quality training. Because the practice teaching hours are limited, so the students follow the prescribed order completion of wiring equipment in good condition, the only equipment to imitate operation training, not on experimental phenomena were explained and analyzed with the theory of knowledge, cannot form a comprehensive skill system in theory to guide the correct. The disconnection between theory teaching and practice teaching seriously affects the improvement of teaching quality. 


\section{Practice Teaching Reform}

\section{1 introduction to the classroom}

The verification experiment, as the name suggests is to validate the theory of the experiment, the understanding and grasping plays an irreplaceable role in the heavy and difficult knowledge, so the part of experiment demo video into the classroom, improve the students' perceptual knowledge, stimulate students' learning enthusiasm, in reducing the basic experiment hours, effectively improve the teaching effect, course curriculum, power electronic technology, motion control system was adopted in classroom teaching with experimental teaching mode, experiment with pendant structure or experimental box to complete the experiment, circuits and systems were all closed. In the course of experiment, the students are almost mechanical connection, read the experimental data and waveform, lack of independent analysis to solve the problem, the problem solving environment and atmosphere. The power electronic technology, the motion control system of single-phase rectifier regulator, on the principle of automatic control course of typical links, simulation of the electric control course of electromagnetic current relay and a voltage relay experiment into the classroom teaching. Comprehensive, design and research experiments are focused on the physical experiment equipment.

\section{2 project driven practical teaching}

In order to strengthen the understanding of the theoretical knowledge, master and skilled application, stimulate students to learn the driving force, the use of project driven experimental teaching mode, the operation process as shown in figure 1. Set the basic and comprehensive application and research direction according to the curriculum project, for example: in the course of power electronic technology, set up the light brightness regulator, soft starter, switch design and production device power supply, power factor correction etc.. SCM principles in the course set up automatic scoring device, electronic clock, electronic sphygmomanometer, traffic lights, music fountain, etc.. Students complete the project according to the project requirement, after learning training application prospect in various stages of engineering together, students get failure - the experience of success, to achieve to cultivate comprehensive application ability of the theory and practice and the ability to analyze and solve the problems, and fully improve the students' comprehensive quality[2].

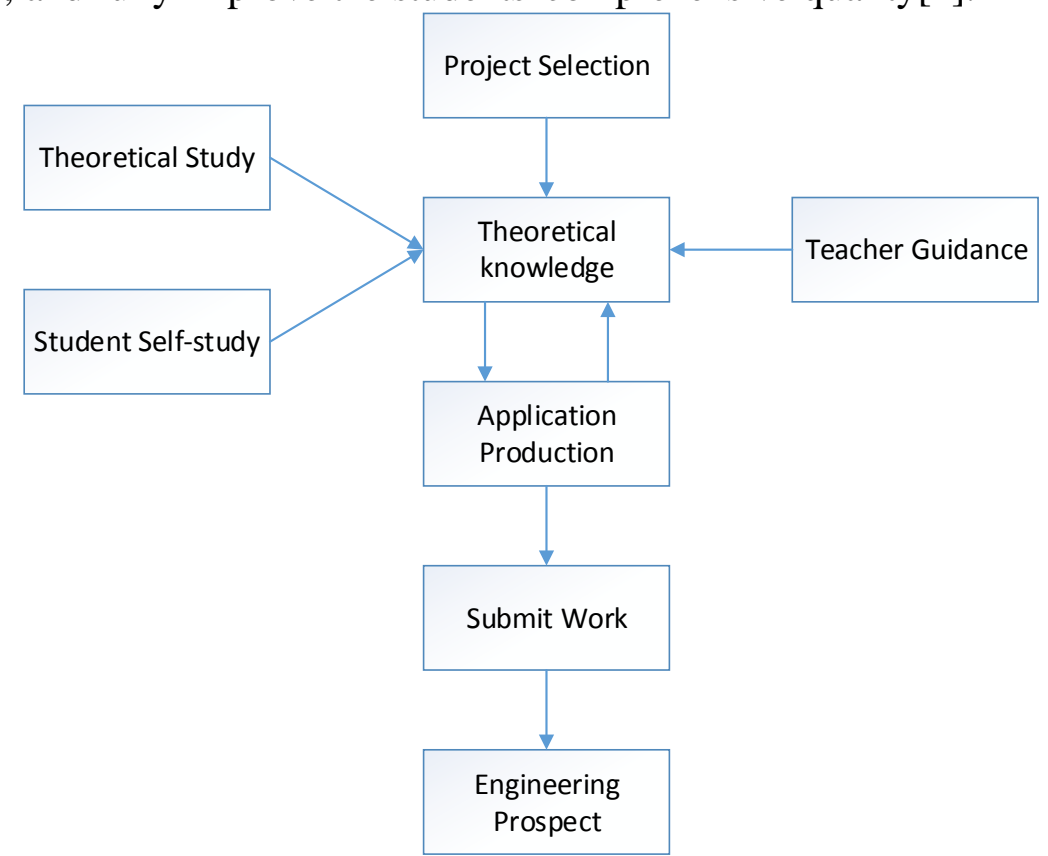

Fig. 1 operation mechanism of project driven practical teaching

\subsection{Virtual and simulation practice teaching}

The specialty of electrical engineering and automation has its special problems in practice teaching:

1) Large investment. For example, the direction of power electronics and power transmission to experimental courses are mostly power devices need three-phase power and inverter, oscilloscope and 
other facilities, one to hundreds of thousands of sets of equipment; high voltage $(500 \mathrm{kV})$ laboratory building, site, insulation, equipment will have tens of millions of investment.

2) The risk is big and cannot be repeated. The most strong due to high voltage, high current, students in practice with a

The equipment will be damaged if it is operated and connected with the live control method.

3) High energy consumption. Electrical engineering and automation of many experimental hardware equipment running high cost, time is limited

The system has the advantages of high energy consumption and low efficiency, so the teaching effect is also limited, which is not consistent with the construction of a resource-saving and environment-friendly society.

Based on the above reasons, it is very important that virtual and simulation practice teaching.

Firstly, the simulation software of MATLAB is introduced, which makes full use of the function of the software to simulate the different characteristics of the circuit. Such as PWM control AC and DC speed control system, automatic control theory and other complex system experiments. The use of the powerful function of the simulation software to achieve the system optimization and extreme control, effectively grasp the dynamic and static characteristics of the system, parameter design, to meet the control requirements, to meet the performance indicators of the system [4].

Secondly, the virtual simulation platform of power system, , the platform has the DC circuit and the AC circuit, control circuit, a multi machine variable ring power network as a variable, analysis of experiment trend, automatic detection, power system control, monitoring and protection the scheduling of power system, has the function of "four remote". The application of virtual simulation platform has been greatly improved in the aspects of economy, security and practicability. It is helpful for students to master the basic experimental methods and operation skills [5].

\section{Conclusion}

Through the reform and exploration of practice teaching in electrical engineering and automation for several years, the practical teaching conditions and abilities have been improved significantly. To fully reflect the dominant position of students, so that it can be combined with practical application, expand horizons, expand thinking, stimulate interest in further exploration, and effectively improve the ability to analyze and solve problems, achieve the purpose and effect of Engineering training.

\section{Acknowledgments}

This work was supported in part by Jiamusi University education and teaching research (No. JYZL2015-05 and No. 2016JC1007) and Heilongjiang higher education reform project (No. JG 2014011046).

\section{References}

[1]. Cai Qin, Wang Qi. Exploration of practical teaching of electrical engineering and automation specialty [J]. Journal of Chengdu Institute of technology, 2015.03;103-106

[2]. Huang Xinbing. "Exploration and application of project driven teaching method" in the reform of power electronic technology course in [J]. University education, 2013, 11:87-88.

[3]. Liu Wei, He Xiaorong, he juan. Electrical engineering and automation professional excellence engineer training mode of [J]. Chinese power education, 2012, 06:58-59.

[4]. Wang Weiguo. Thinking and suggestion on the construction of virtual simulation experiment teaching center $[\mathrm{J}]$. Laboratory research and exploration, 2013,12:5-8

[5]. Wending Ma, Wu Zuowu et al. Mining engineering virtual simulation experimental teaching system construction and practice of the [J]. Experimental technology and management, 2014,09 (7); 14-16 